\title{
EFFECT OF HYPOTENSIVE EPIDURAL ANAESTHESIA ON ACETABULAR CEMENT-BONE FIXATION IN TOTAL HIP ARTHROPLASTY
}

\author{
CHITRANJAN S. RANAWAT, WALTER B. BEAVER, NIGEL E. SHARROCK, MICHAEL J. MAYNARD, \\ BARBARA URQUHART, ROBERT SCHNEIDER
}

From the Hospital for Special Surgery, New York

\begin{abstract}
We selected 20 matched pairs of patients who had had total hip arthroplasty by the same surgeon using the same cemented technique. Matching was by age, sex, height, weight and diagnosis. One of each pair had received hypotensive epidural anaesthesia, with less than $300 \mathrm{ml}$ blood loss: the other had normotensive general anaesthesia with more than $500 \mathrm{ml}$ of blood loss.

Early postoperative radiographs were evaluated independently by three blinded observers, using a scoring criteria which assessed the quality of the cement-bone interface. The results showed that patients who had received epidural anaesthesia had significantly better radiographic scores $(p<0.02)$. Our findings suggest that hypotensive anaesthesia facilitates penetration of cement into bone.
\end{abstract}

Aseptic loosening is the most common cause of failure of cemented total hip arthroplasty and often requires revision surgery (Cupic 1979; Dobbs 1980; Chandler et al 1981; Gustilo and Burnham 1982; Dorr, Takei and Conaty 1983; Collis 1984; Ranawat et al 1984; Cornell and Ranawat 1986b; Dall et al 1986; Wroblewski 1986; McCoy et al 1988; Kavanagh et al 1989; Ranawat, Hansraj and Neves 1989b; Ranawat, Rawlins and Harju 1989a). The quality of the cement-bone micro-interlock is an important factor for the durability of fixation of both acetabular and femoral components (Cornell and Ranawat 1986a; Benjamin et al 1987; Ranawat et al 1989a). It would therefore be useful to analyse methods of improving this micro-interlock.

Intra-operative techniques to achieve this on the acetabular side include the preservation of subchondral bone, the use of multiple fixation holes and of pulsed

C. S. Ranawat, MD, Professor of Orthopaedic Surgery, Cornel University Medical School, Attending Orthopaedic Surgeon

N. E. Sharrock, MB, ChB, Attending Anaesthesiologist

M. J. Maynard, MD, Fellow in Orthopaedic Surgery

B. Urquhart, RN, BSN, Department of Anaesthesia

R. Schneider, MD, Associate Professor of Clinical Radiology, Cornell

University Medical College, Attending Radiologist

Hospital for Special Surgery, 535 East 70th Street, New York, NY 10021, USA.

W. B. Beaver, MD, Attending Orthopaedic Surgeon

Miller Orthopaedic Clinic, 1001 Blythe Boulevard, Charlotte, North Carolina 28203, USA.

Correspondence should be sent to Dr C. S. Ranawat.

(C) 1991 British Editorial Society of Bone and Joint Surgery

0301-620X/91/5233 $\$ 2.00$

J Bone Joint Surg [Br] 1991; 73-B:779-82. lavage, the pressurisation of cement, and hypotensive anaesthesia for a relatively bloodless field (DeLee and Charnley 1976; Lee and Ling 1981; Krause et al 1982; Dorr et al 1984; Ranawat et al 1989a). The role of hypotensive anaesthesia has not been fully investigated, though it has been suggested that a layer of blood on the surface of the bone might create a hydraulic barrier and impair ingress of cement into the interstices of cancellous bone. Furthermore, it is possible that a layer of blood between cement and bone might ultimately form a fibrous tissue barrier (DeLee and Charnley 1976; Lee and Ling 1981; Eftekhar and Nercessian 1988; Bannister et al 1990). In either circumstance, the weak cement-bone interface could result in reduced strength under shear and tension stresses, leading eventually to micromotion, and to failure (Benjamin et al 1987).

We have assessed the effect of hypotensive anaesthesia on the micro-interlock between bone and cement of the acetabular component.

\section{MATERIALS AND METHODS}

We identified 20 matched pairs of patients, selected from a retrospective review of 650 primary total hip arthroplasties performed by the same surgeon (CSR) for osteoarthritis or rheumatoid arthritis from 1984 to 1987. Patients were matched by age (within five years), sex, height (within $8 \mathrm{~cm}$ ), weight (within $5 \mathrm{~kg}$ ) and diagnosis. Pairing was by the type of anaesthesia used: one of each pair had a normotensive technique and the other a hypotensive method.

The normotensive group of patients had general 
endotracheal anaesthesia, with the systolic pressure maintained at or above $110 \mathrm{mmHg}$ throughout the operation. Anaesthesia was induced with pentothal and succinylcholine and maintained with nitrous oxide, oxygen, and isoflurane. In this group the intra-operative blood loss was $500 \mathrm{ml}$ or more.

Patients in the hypotensive group had epidural anaesthesia with $0.75 \%$ bupivacaine injected at the $\mathrm{L} 2-3$ or L3-4 interspaces in sufficient doses to achieve an anaesthetic level at T4 or above. Blood pressure was supported with low dose epinephrine infusions and, if necessary, reduced by intravenous infusion of sodium nitroprusside. These hypotensive patients were sedated but awake, breathing spontaneously with a mean arterial pressure of 50 to $55 \mathrm{mmHg}$ recorded constantly from a line in the ipsilateral radial artery; their intra-operative blood loss was $<300 \mathrm{ml}$. Both groups of patients received Ringer's lactate intra-operatively for fluid replacement.

All the operations were performed in the lateral decubitus position using a posterolateral approach; the same technique was used throughout the study period. This included the preservation of subchondral bone, the use of pulsed lavage and multiple fixation holes with pressurisation of doughy Simplex cement (Howmedica, USA).

Technique of socket fixation. All 40 sockets were implanted by the following method:

The reamed socket was $2 \mathrm{~mm}$ larger than the outer diameter of the prosthesis, to provide clearance for a uniform cement mantle. Multiple $5 \mathrm{~mm}$ by $5 \mathrm{~mm}$ fixation holes were made using a high-speed, air-driven, collared drill. Two relatively large $(10 \mathrm{~mm}$ by $10 \mathrm{~mm})$ holes were made in the ischium and pubis; the sites for these were usually obvious in the exposed cancellous bone. The prepared cavity was cleaned with a water pick and dried by packing the holes with a sponge while the cement was mixed. The timing of these preparations is critical.

We used Simplex cement because of its superior intrusion properties, strength, and handling characteristics. The cement reagents were heated in a blanket warmer to speed up the rate of curing; this also seems to aid the release of trapped air. The powder and liquid monomers were mixed with minimum stirring (usually less than 30 seconds) and the cement was allowed to lie undisturbed in the bowl for several minutes - during which time most of the trapped air bubbles escaped to the surface. Simplex cement, three to five minutes after mixing, is slightly firmer than toothpaste. Some cement was coated over the outer surface of the prosthesis and

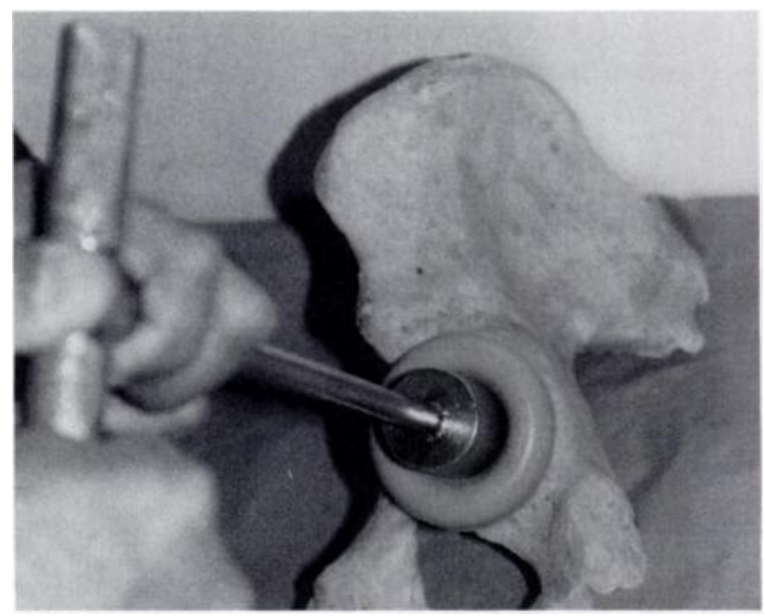

Fig. 1

The use of the acetabular cement pressurisation tool is demonstrated on a cadaver specimen.

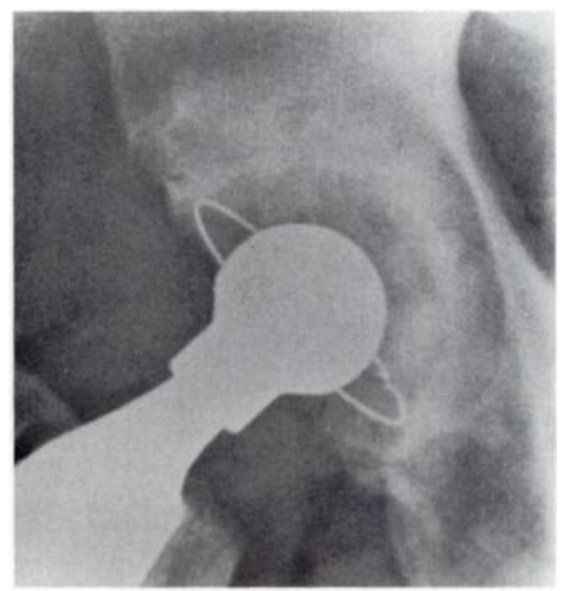

Fig. 2

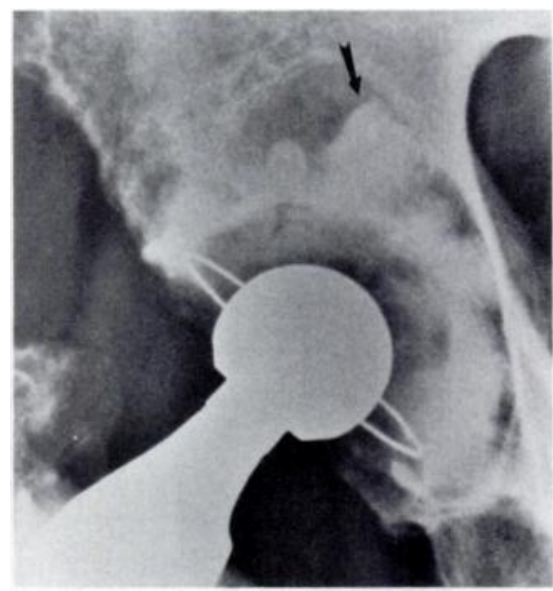

Fig. 3

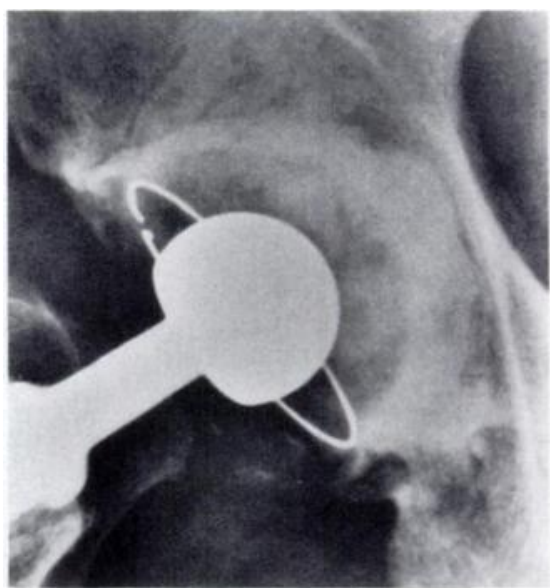

Fig. 4

Figure 2 - An optimal cement-bone interface on an anteroposterior radiograph, showing gradual merging of the cement into the cancellous bone. Figure 3 - There is no radiolucency at the bone-cement interface, but rounding-off of the cement front suggests incomplete micro-interlock. The rounding-off indicated by the arrow resulted from the incomplete curettage of a subchondral cyst. Figure $4-$ Radiolucent lines of $<1 \mathrm{~mm}$ are seen in all three zones, indicating poor cement-bone micro-interlock. 
the remainder was placed in the carefully dried acetabulum, digitally pressed into the fixation holes and then pressurised, using a sturdy rubber balloon (Fig. 1), for two to three minutes.

Any blood which collected on the cement was cleaned off with a dry sponge before the prosthetic socket, in its appropriate holder, was inserted into the cement. It was pressed into position with about $40^{\circ}$ of lateral opening and $15^{\circ}$ of anteversion. Pressure was maintained on the prosthesis while the cement hardened, with digital pressure on any part of the cement mantle uncovered by bone.

Method of assessment. Assessment of the cement-bone interface was performed on good quality anteroposterior pelvic radiographs taken between one and two months after surgery. The appearance of the cement-bone interface was classified into three grades:

Grade 1 signified perfect cement-bone interlock with gradual merging of cement into the cancellous bone with no radiolucency or rounding-off of the cement front (Fig. 2).

Grade 2 demonstrated no radiolucency but there was rounding-off of the cement front (Fig. 3).

Grade 3 had both rounding-off and radiolucencies (Fig. 4).

For each acetabulum, a score was determined in each of the three zones of Charnley. Thus, the optimal score for acetabular cement-bone interlock was 3, and the worst score was 9 (Table I). This grading of the interface was performed by three independent observers, two orthopaedic surgeons and one radiologist, who were appropriately blinded to the type of anaesthesia used for each patient.

Table I. Radiographic scores for the quality of the acetabular cement-bone interface (see text), in each of the three zones of Charnley, for matched pairs of normotensive and hypotensive patients

\begin{tabular}{|c|c|c|c|c|c|c|c|c|c|}
\hline \multirow[b]{3}{*}{ Pair } & \multirow[b]{3}{*}{ Sex } & \multicolumn{4}{|c|}{ Normotensive } & \multicolumn{4}{|c|}{ Hypotensive } \\
\hline & & \multicolumn{3}{|c|}{ Zone } & \multirow[b]{2}{*}{ Total } & \multicolumn{3}{|c|}{ Zone } & \multirow[b]{2}{*}{ Total } \\
\hline & & 1 & 2 & 3 & & 1 & 2 & 3 & \\
\hline 1 & $\mathbf{M}$ & 3 & 1 & 1 & 5 & 2 & 2 & 1 & 5 \\
\hline 2 & $\mathbf{M}$ & 3 & 3 & 2 & 8 & 1 & 1 & 2 & 4 \\
\hline 3 & $\mathbf{M}$ & 3 & 1 & 1 & 5 & $i$ & $i$ & 1 & 3 \\
\hline 4 & $\mathbf{M}$ & 2 & i & 1 & 4 & 1 & 1 & 1 & 3 \\
\hline 5 & $\mathbf{M}$ & 2 & 2 & 3 & 7 & 1 & 1 & 1 & 3 \\
\hline 6 & M & 3 & 2 & 3 & 8 & 3 & 2 & 2 & 7 \\
\hline 7 & $\mathbf{M}$ & 1 & 2 & 1 & 4 & 1 & 1 & 1 & 3 \\
\hline 8 & $\mathbf{M}$ & 3 & 3 & 2 & 8 & 2 & 2 & 3 & 7 \\
\hline 9 & $\mathbf{M}$ & 2 & 3 & 2 & 7 & $i$ & 1 & 1 & 3 \\
\hline 10 & $\mathbf{M}$ & 1 & 1 & 1 & 3 & $i$ & $i$ & $i$ & 3 \\
\hline 11 & $\mathbf{F}$ & $i$ & $i$ & $i$ & 3 & $i$ & i & i & 3 \\
\hline 12 & $\mathrm{~F}$ & 2 & $i$ & $i$ & 4 & i & i & i & 3 \\
\hline 13 & $F$ & 2 & $i$ & 2 & 5 & i & i & 1 & 3 \\
\hline 14 & $F$ & 1 & 2 & 2 & 5 & 1 & 1 & 1 & 3 \\
\hline 15 & $\mathrm{~F}$ & 3 & 3 & 2 & 8 & $i$ & 2 & $i$ & 4 \\
\hline 16 & F & 1 & 1 & 1 & 3 & 1 & 1 & 1 & 3 \\
\hline 17 & $\mathrm{~F}$ & 2 & 2 & 2 & 6 & 3 & $i$ & 1 & 5 \\
\hline 18 & $\mathrm{~F}$ & 3 & 2 & 3 & 8 & 1 & i & $i$ & 3 \\
\hline 19 & $\mathrm{~F}$ & 1 & 1 & 1 & 3 & i & i & 1 & 3 \\
\hline 20 & $\mathrm{~F}$ & 1 & 1 & 1 & 3 & 3 & 3 & 1 & 7 \\
\hline
\end{tabular}

The results were analysed by comparing the scores in the normotensive patients with those of the matched hypotensive patients, using the Mann-Whitney test for non-parametric data and the McNemar contingency tables.

\section{RESULTS}

The total score for all three zones was significantly better for the hypotensive patients than for the normotensive patients $(p<0.02)$. When each of the Charnley zones is taken separately the hypotensive group scored better in each zone $(p<0.06$ for zone $1 ; p<0.09$ for zone 2 ; $p<0.03$ for zone 3). Fourteen of the hypotensive group had a better score than the paired normotensive acetabulum, five pairs had nearly identical scores and in only one pair did the normotensive acetabulum achieve a better score. The non-random character of this distribution is significant $(\mathrm{p}<0.0001)$.

\section{DISCUSSION}

We chose a study design using retrospective matched pairs rather than a prospective randomised method for several reasons. First, it was considered unethical to deliberately increase blood loss by using a normotensive anaesthetic in a prospective manner, as this might expose patients to the added risk of homologous blood transfusions. Secondly, the retrospective evaluation of a large patient population, allowed close matching of cases with similar age, height, weight, and sex. These factors have been cited as having an influence upon the fixation of components and durability of the total hip replacement (Ranawat et al 1984; Cornell and Ranawat 1986b). Finally, the retrospective review enabled us to identify closely matched pairs of patients with different anaesthetic techniques and disparate intra-operative blood losses.

Acetabular fixation is traditionally assessed by anteroposterior radiographs of the pelvis. We developed a new grading system, using three grades of fixation in each of the three zones of Charnley. The three independent observers showed good agreement, with interobserver differences in only three of the 120 zones analysed.

Epidural anaesthesia is associated with less intraoperative blood loss than general anaesthesia (Sharrock, Mineo and Urquhart 1989), though general anaesthesia with hypotension can also reduce blood loss (Thompson et al 1978; Vazeery and Lunde 1979). Our experience is that the driest surgical fields are obtained by using epidural anaesthesia with hypotension. Many anaesthetists and orthopaedic surgeons hesitate to use hypotensive anaesthesia in high-risk or elderly patients for fear of peri-operative complications, but clinical experience of this method in over 3000 cases at the Hospital for Special Surgery (Sharrock et al 1989) has shown a very low incidence of postoperative myocardial infarction, stroke, or renal infarction. 
The concept that blood at the cement-bone interface may impair the quality of fixation is not new (DeLee and Charnley 1976; Benjamin et al 1987; Eftekhar and Nercessian 1988; Bannister et al 1990) and various methods aimed at reducing bleeding at the interface have been tried in the past. The results of our study support the assertion that the most effective way to reduce blood at the interface is by the use of hypotensive anaesthesia (Bannister et al 1990).

Blood, oozing from the cancellous bone of the acetabulum, may form a liquid layer between the surface of the bone and the cement front, preventing ingress of cement into the interstices of the bone, and impairing the quality of the micro-interlock (Krause et al 1982; Benjamin et al 1987). Such blood would subsequently resorb, leaving a gap between the cement and bone which is replaced by fibrous tissue (Cupic 1979). This layer of soft tissue could well create the conditions for subsequent loosening, especially in active, young or heavy patients over a long period of time. It has also been suggested that one of the reasons for the excellent longterm results of cemented total knee arthroplasty is the dry field achieved by the use of an intra-operative tourniquet (Ranawat and Rose 1985).

In our 20 matched pairs of patients, the use of epidural anaesthesia with hypotension gave a better radiographic appearance at the cement-bone interface than was seen in normotensive patients $(p<0.02)$. Radiographic evidence of failure is commonly seen in the acetabulum (Wroblewski 1986). It is frequently asymptomatic and may not need revision unless migration occurs or the patient develops pain. By contrast, radiographic loosening of the femoral component, once established, usually requires revision (Ranawat et al 1984; Pellicci et al 1985). It is probable that the improved fixation observed in the acetabulum in patients after hypotensive anaesthesia also occurs within the shaft of the femur.

Longer term follow-up will be required to confirm that the postoperative radiographic appearance of acetabular interlock is related to subsequent loosening, but we predict that hips implanted with improved cement technique and under hypotension will remain well fixed for a longer time. Therefore, we recommend that hypotensive anaesthesia is used whenever possible for patients undergoing cemented total hip arthroplasty. We prefer an epidural hypotensive technique.

No benefits in any form have been received or will be received from a commercial party related directly or indirectly to the subject of this article.

\section{REFERENCES}

Bannister GC, Young SK, Baker AS, Mackinnon JG, Magnusson PA. Control of bleeding in cemented arthroplasty. J Bone Joint Surg [Br] 1990; 72-B:444-6.

Benjamin JB, Gie GA, Lee AJC, Ling RSM, Volz RG. Cementing technique and the effects of bleeding. J Bone Joint Surg [Br] 1987; 69-B :620-4.
Chandler HP, Reineck FT, Wixson RL, McCarthy JC. Total hip replacement in patients younger than thirty years old: a five-year follow-up study. J Bone Joint Surg [Am] 1981; 63-A :1426-34.

Collis DK. Cemented total hip replacement in patients who are less than fifty years old. J Bone Joint Surg [ Am] 1984; 66-A :353-9.

Cornell CN, Ranawat CS. The impact of modern cement techniques on acetabular fixation in cemented total hip replacement. $J$ Arthroplasty 1986a; $1: 197-202$.

Cornell CN, Ranawat CS. Survivorship analysis of total hip replacements : results in a series of active patients who were less than fiftyfive years old. J Bone Joint Surg [Am] 1986b; 68-A :1430-4.

Cupic Z. Long-term follow-up of Charnley arthroplasty of the hip. Clin Orthop 1979; $141: 28-43$.

Dall DM, Grobbelaar CJ, Learmonth ID, Dall G. Charnley low-friction arthroplasty of the hip. Clin Orthop 1986; $211: 85-90$.

DeLee JG, Charnley J. Radiological demarcation of cemented sockets in total hip replacement. Clin Orthop 1976; $121: 20-32$.

Dobbs HS. Survivorship of total hip replacements. J Bone Joint Surg [Br] $1980 ; 62-\mathrm{B}: 168-73$.

Dorr LD, Lindberg JP, Claude-Fangere M, Malluche HH. Factors influencing the intrusion of methylmethacrylate into human tibiae. Clin Orthop 1984; 183:147-52.

Dorr LD, Takei GK, Conaty JP. Total hip arthroplasties in patients less than forty-five years old. J Bone Joint Surg [Am] 1983; 65-A: 474-9.

Eftekhar NS, Nercessian O. Incidence and mechanism of failure of cemented acetabular component in total hip arthroplasty. Orthop Clin North Am 1988; 19:557-66.

Gustilo RB, Burnham WH. Long-term results of total hip arthroplasty in young patients. In: Nelson JP, ed. The Hip. Procs of the 10th meeting of the Hip Society. St Louis, etc: CV Mosby Co, $1982: 27-33$.

Kavanagh BF, Dewitz MA, Ilstrup DM, Stauffer RN, Coventry MB. Charnley total hip arthroplasty with cement : fifteen year results. $J$ Bone Joint Surg [Am] 1989; 71-A:1496-503.

Krause WR, Krug W, Eng B, Miller J. Strength of the cement-bone interface. Clin Orthop 1982; 163:290-9.

Lee AJC, Ling RSM. Improved cementing techniques. AAOS Instruction Course Lecture 1981; 30:407-13.

McCoy TH, Salvati EA, Ranawat CS, Wilson PD, Jr. A fifteen-year follow-up study of one hundred Charnley low-friction arthroplasties. Orthop Clin North Am 1988; 19:467-76.

Pellicci PM, Wilson PD Jr, Sledge CB, et al. Long-term results of revision total hip replacement: a follow-up report. $J$ Bone Joint Surg $[A m] 1985 ; 67-A: 513-6$.

Ranawat CS, Atkinson RE, Salvati EA, Wilson PD Jr. Conventional total hip arthroplasty for degenerative joint disease in patients between the ages of forty and sixty years. J Bone Joint Surg [Am] $1984 ; 66-A: 745-52$.

Ranawat CS, Rose HA. Clinical and radiographic results of totalcondylar knee arthroplasty: a 3- to 8-year follow-up. In: Ranawat CS, ed. Total-Condylar knee arthroplasty: technique, results and complications. New York, etc: Springer-Verlag, 1985:140-8.

Ranawat CS, Rawlins BA, Harju VT. Effect of modern cement technique on acetabular fixation total hip arthroplasty: a retrospective study in matched pairs. Orthop Clin North Am 1989a; 19: 599-603.

Ranawat CS, Hansraj KK, Neves M. A seventeen year survivorship study of Charnley total hip replacement. Orthop Trans 1989b; $13: 62$.

Sharrock NE, Mineo R, Urquhart B. Is hypotensive anaesthesia safe in treated hypertensive patients? Experience with epidural anaesthesia. Anesth Analg 1989; 68 Supp I:S256.

Thompson GE, Miller RD, Stevens WC, Murray WR. Hypotensive anesthesia for total hip arthroplasty: a study of blood loss and organ function (brain, heart, liver and kidney). Anesthesiology $1978 ; 48: 91-6$.

Vazeery AK, Lunde $\mathbf{O}$. Controlled hypotension in hip joint surgery: an assessment of surgical haemorrhage during sodium nitroprusside infusion. Acta Orthop Scand 1979; 50:433-41.

Wroblewski BM. 15-21-year results of the Charnley low-friction arthroplasty. Clin Orthop 1986; $211: 30-5$. 